\title{
Characterization and resuscitation of 'non-culturable' cells of Legionella pneumophila
}

\author{
Adrien Ducret ${ }^{1,2}$, Maïalène Chabalier ${ }^{1}$ and Sam Dukan ${ }^{1 *}$
}

\begin{abstract}
Background: Legionella pneumophila is a waterborne pathogen responsible for Legionnaires' disease, an infection which can lead to potentially fatal pneumonia. After disinfection, L. pneumophila has been detected, like many other bacteria, in a "viable but non culturable" state (VBNC). The physiological significance of the VBNC state is unclear and controversial: it could be an adaptive response favoring long-term survival; or the consequence of cellular deterioration which, despite maintenance of certain features of viable cells, leads to death; or an injured state leading to an artificial loss of culturability during the plating procedure. VBNC cells have been found to be resuscitated by contact with amoebae.

Results: We used quantitative microscopic analysis, to investigate this "resuscitation" phenomenon in $L$. pneumophila in a model involving amending solid plating media with ROS scavengers (pyruvate or glutamate), and co-culture with amoebae. Our results suggest that the restoration observed in the presence of pyruvate and glutamate may be mostly due to the capacity of these molecules to help the injured cells to recover after a stress. We report evidence that this extracellular signal leads to a transition from a not-culturable form to a culturable form of $L$. pneumophila, providing a technique for recovering virulent and previously uncultivated forms of L. pneumophila.
\end{abstract}

Conclusion: These new media could be used to reduce the risk of underestimation of counts of virulent of L. pneumophila cells in environmental samples.

\section{Background}

Legionella pneumophila is a waterborne pathogen that can survive in a wide range of environmental conditions [1]. It is the etiological agent of Legionnaires' disease, which can progress to fatal pneumonia [2]. Transmission between individuals is not observed, but aerosol transmission from the aquatic environment to humans is now well documented [1-4]. After inhalation and dissemination into the lungs, L. pneumophila invades alveolar macrophages where it multiplies intracellularly. The presumed natural reservoir for this pathogen in the environment is amoebae, where L. pneumophila can invade and replicate [5,6]. L. pneumophila switches between two forms - a non-motile, thin-walled replicative form and a motile, thick-walled transmissive form - allowing

\footnotetext{
* Correspondence: sdukan@imm.cnrs.fr

${ }^{1}$ Aix Marseille Université, Laboratoire de Chimie Bactérienne (UMR7283), Institut de Microbiologie de la Méditerranée - CNRS, 31, Chemin Joseph Aiguier, 13402 Marseille, France

Full list of author information is available at the end of the article
}

it to survive in the face of environmental fluctuations $[7,8]$. These two phases of the L. pneumophila life cycle are reciprocal and the transition between them is triggered by the amount of available nutrients [9-11]. In favorable conditions, transmissive traits are repressed, enabling L. pneumophila to replicate profusely. By contrast, when nutrients become limiting, L. pneumophila cells stop replicating and express virulence factors that mediate survival and dispersal in the environment. By comparison with the replicative form, the transmissive form is characterized by cell motility, osmotic resistance, sodium sensitivity, cytotoxicity and the ability to avoid phagosome-lysosome fusion [10]. Under certain conditions, transmissive L. pneumophila develop into 'mature intracellular forms' that can persist in the environment [12].

Prevention and eradication of L. pneumophila contamination of man-made water systems is required to avoid and control legionellosis outbreaks. For this purpose, a large range of physical, thermal and chemical methods

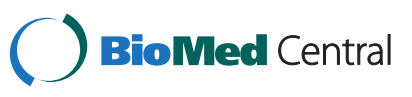


are used, including metal ions (copper and silver), UV light, and oxidizing and non-oxidizing agents [13,14]. L. pneumophila has been detected in a "viable but non culturable" (VBNC) state immediately after such disinfection [15-19]; the VBNC state is a physiological state in which bacteria cannot grow on standard growth media but retain certain features of viable cells, such as cellular integrity, metabolic activity or virulence [20]. The physiological significance of the VBNC state is unclear and controversial: it could be an adaptive response favoring longterm survival under adverse conditions [21,22] (referred to hereafter as adaptive-VBNC or A-VBNC cells) or the consequence of cellular damage which despite the maintenance of some features of viable cells leads to death (damaged VBNC or D-VBNC cells) [23-25].

It has been reported that apparently dead cells could be restored to viability on agar plates supplemented with compounds that degrade or block the formation of reactive oxygen species (ROS) [26-35]. Various stresses, including starvation, hypochlorous acid $(\mathrm{HOCl})$ and heat shock, may leave cells in a vulnerable physiological state (injured state) in which atmospheric oxygen, during the plating procedure, may amplify cellular damage leading to an artifactual loss of culturability [26-35]. In other words, cells detected as VBNC may be A-VBNC cells or D-VBNC cells or cells in an injured state. The existence of A-VBNC or injured pathogen cells is a public health concern since they would not be detected as possible sources of infection, and may nevertheless retain their pathogenicity. For instance, samples containing L. pneumophila have been exposed to starvation, monochloramine or $\mathrm{HOCl}$, and as a result contained no detectable culturable cells; however, L. pneumophila was resuscitated by contact with amoebae $[16,18,36,37]$, suggesting that non-culturable L. pneumophila cells were still able to invade amoebae and replicate. However, this "resuscitation" phenomenon may simply reflect the presence of injured or A-VBNC cells.

We used quantitative microscopic analysis, and a model system involving amending solid plating media with ROS scavengers, and co-culture with amoebae, to investigate this "resuscitation" phenomenon. We show that including the ROS scavengers, pyruvate and glutamate, in standard medium (BCYE) may reduce underestimation of the counts of pathogenic and not-culturable forms of $L$. pneumophila in environmental samples. Our findings indicate that the restoration observed in the presence of pyruvate and glutamate may be largely due to these compounds facilitating the recovery of injured cells after a stress.

\section{Results}

Two sub-populations of viable $L$. pneumophila cells were observed before and after a $\mathrm{HOCl}$ treatment

To confirm previous detection of VBNC cells (A-VBNC cells D-VBNC cells plus injured cells) of $L$. pneumophila
[15-19], the culturability and the viability of a suspension of $L$. pneumophila cells harvested at the beginning of stationary phase was investigated before and after a $\mathrm{HOCl}$ treatment (see Methods). Culturability was determined on the standard medium (BCYE) and cell viability was assessed using a ChemChrome V6 Kit (CV6). This assay kit is widely used to discriminate metabolically active cells (which become fluorescent) from dead cells (which do not fluoresce), and has been used to detect VBNC L. pneumophila cells $[18,38,39]$. As expected, the number of culturable and viable cells decreased as the $\mathrm{HOCl}$ concentration increased, but the total number of cells observed did not change significantly (Figure 1A). Viable counts determined by CV6 were significantly higher $(\mathrm{p}<0.05)$ than CFU counts in all samples, indicating the presence of VBNC cells even in samples not treated with $\mathrm{HOCl}$ (Figure 1A).

CV6 is a fluorogenic ester which is converted to free fluorescein by cytoplasmic esterases. Since the concentration of fluorescent fluorescein trapped in metabolically active cells increases over the time as a function of esterase activity, the level of fluorescence is a marker of the specific metabolic activity at the single-cell level. We therefore followed the distribution of fluorescence in the viable cells before and after the $\mathrm{HOCl}$ treatment (Figure 1B). The distribution of the fluorescence intensity was not uniform: there were distinct peaks of cell numbers at certain intensities suggesting that the population of cells was composed of distinct sub-populations of viable cells with different degrees of metabolic activity. Two sub-populations with normal and overlapping distributions were observed even before the $\mathrm{HOCl}$ treatment: a sub-population centered to the average value of fluorescence intensity $\left(1.52 \times 10^{8}\right.$ cells.mll $\left.^{-1}\right)$, albeit showing some diversity in values, and subsequently referred as subpopulation $M$ (medium), and a subpopulation with high, and more similar, values of the fluorescence intensity $\left(1.55 \times 10^{8}\right.$ cells.ml $\left.^{-1}\right)$, referred to as subpopulation $\mathrm{H}$ (high). When this analysis was repeated with cells were harvested during exponential growth, only one of these two subpopulations, subpopulation $\mathrm{M}$ was observed (Figure $1 \mathrm{C}$ ).

At very low $\mathrm{HOCl}$ concentration $(0.03 \mathrm{mM} ; 52 \%$ of culturable cells; $95 \%$ of viable cells), subpopulation $\mathrm{H}$

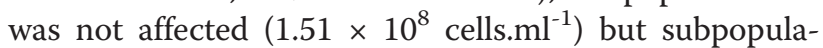
tion $\mathrm{M}$ was substantially reduced $\left(0.73 \times 10^{8}{\left.\text { cells. } l^{-1}\right)}^{-}\right.$ with the concomitant apparition of a new subpopulation

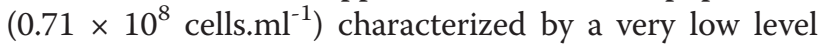
of fluorescence (subpopulation L). At $\mathrm{HOCl}$ concentrations associated with a decrease in the CFU counts ( $0.13 \mathrm{mM} ; 1.6 \%$ of culturable cells; $81 \%$ of viable cells), subpopulation $\mathrm{H}$ was again not substantially affected $\left(1.11 \times 10^{8}\right.$ cells.ml $\left.^{-1}\right)$ whereas the subpopulation $\mathrm{M}$ was almost undetectable, subpopulation $\mathrm{L}$ was large $(2.58 \times$ 


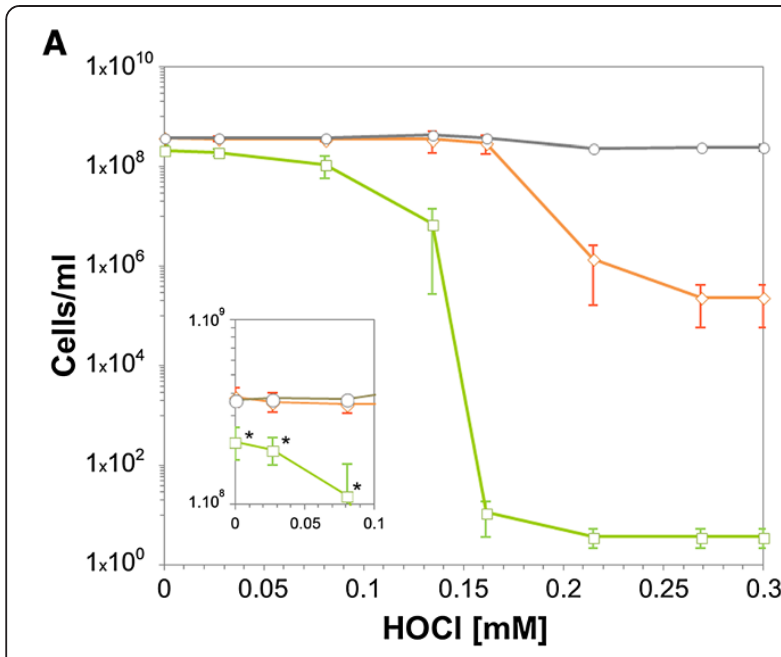

B
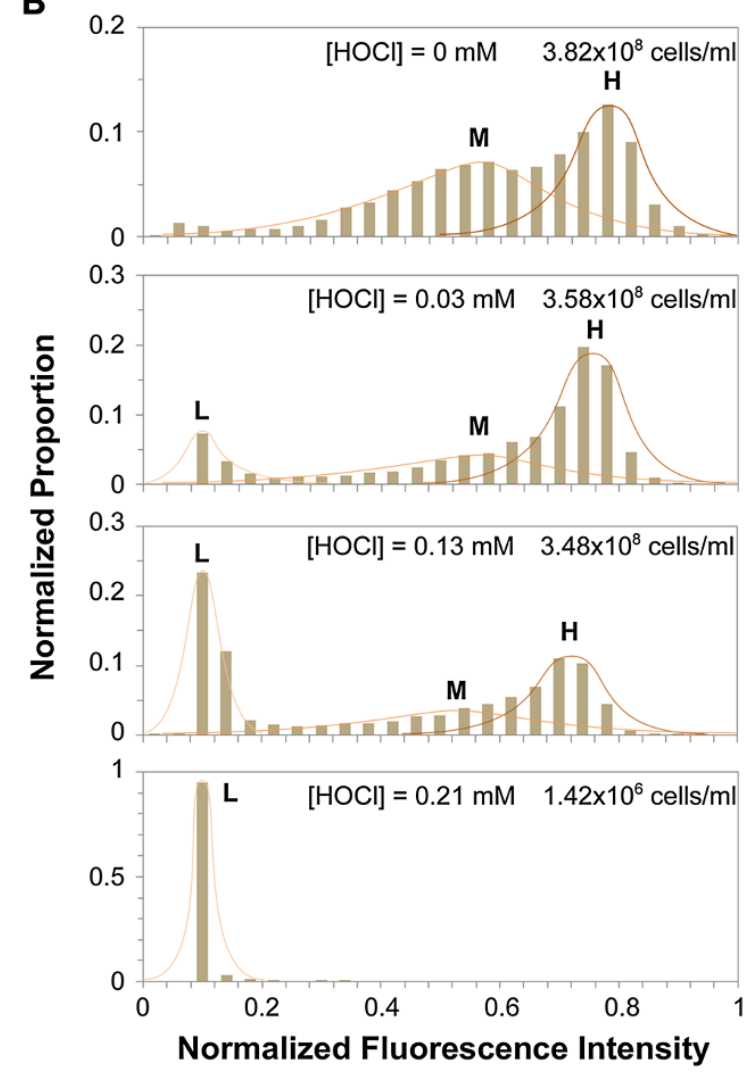

C

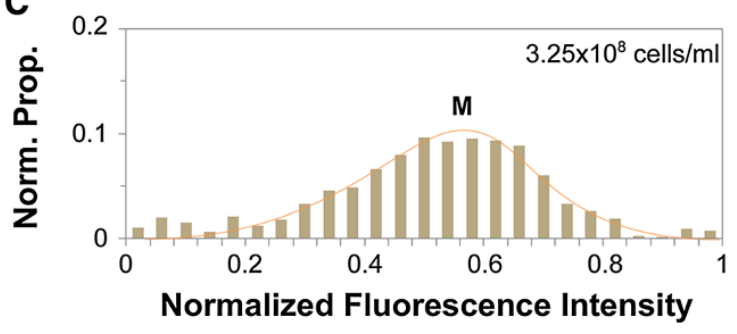

Figure 1 Culturability and viability of $L$. pneumophila Philadelphia cells harvested at the beginning of stationary phase, before and after $\mathrm{HOCl}$ treatment. (A) Number of culturable cells as assessed on the standard medium ( $\square$ ), total number of cells detected using DAPI procedure $(0)$, and viable cells detected using the CV6 procedure $(\diamond)$ as a function of $\mathrm{HOCl}$ concentration $(\mathrm{mM})$. The values reported are the means of three independent experiments (Errors bars $=$ SD). Inset shows a close-up of the part of the plot corresponding to $\mathrm{HOCl}$ concentrations lower than $0.1 \mathrm{mM}$. Stars indicate that the number of culturable cells was significantly lower $(p<0.05)$ than the total number of cells. (B) Distribution of the normalized fluorescence intensity of the viable cells detected using the $\mathrm{CV} 6$ procedure as a function of $\mathrm{HOCl}$ concentration. Subpopulations were named according to their relative fluorescence intensity: L (Low), M (Medium) and H (High). (C) Distribution of the normalized fluorescence intensity of viable cells detected using the CV6 procedure in samples harvested from a culture in the exponential growth phase. For each condition, at least 3000 cells were analyzed. Similar results were obtained in two other independent experiments.

$10^{8}$ cells.ml $\left.^{-1}\right)$. At the highest concentration of $\mathrm{HOCl}$ $\left(0.21 \mathrm{mM} ; 1.6 \times 10^{-6} \%\right.$ of culturable cells; $0.6 \%$ of viable cells), neither subpopulation $\mathrm{M}$ nor $\mathrm{H}$ was detected, and only subpopulation $\mathrm{L}$ was observed.

These findings indicate that there are at least two subpopulations of metabolically active cells in L. pneumophila cultures harvested at the beginning of the stationary phase. Interestingly, these two subpopulations were affected differently by treatment with the biocide $\mathrm{HOCl}$ : the most metabolically active subpopulation $(\mathrm{H})$ was more resistant than the less active subpopulation $(\mathrm{M})$, and appeared to be the majority subpopulation among the VBNC cells observed after moderate $\mathrm{HOCl}$ treatment (0.03-0.13 mM).

\section{The culturability of a VBNC cell subpopulation on standard medium was restored by the presence of pyruvate and/or glutamate}

The detection of VBNC cells upon treatment with $\mathrm{HOCl}$ displaying metabolic activity close to the level observed in absence of treatment (population $\mathrm{H}$ ), suggest that these cells were still active but unable to form colonies on agar plates. There have been numerous reports that apparently dead cells (injured cells) could be reactivated by inclusion of ROS scavengers in agar plates [26-35]. We therefore added various concentrations of compounds that degrade or block the formation of ROS to standard medium (BCYE) (Table 1). L. pneumophila cultures were treated with $0.21 \mathrm{mM} \mathrm{HOCl}$ and plated on the various media. The ratio of cells counts on supplemented medium to that on standard medium was calculated as a measure of recovery. This ratio was higher than 1 only for pyruvate and glutamate: these compounds thus promoted the recovery of presumably injured cells. The highest recovery ratio was observed in 
Table 1 Restoration ratio in presence of supplements

\begin{tabular}{|c|c|}
\hline Supplements & Restoration rati \\
\hline \multicolumn{2}{|c|}{ Sodium Pyruvate [\%] } \\
\hline 0.1 & $1.1 \pm 0.2$ \\
\hline 0.5 & $154.8 \pm 11$ \\
\hline 1 & $62.5 \pm 25$ \\
\hline \multicolumn{2}{|l|}{ Glutamate [\%] } \\
\hline 0.1 & $0.7 \pm 0.6$ \\
\hline 0.5 & $3.0 \pm 0.2$ \\
\hline 1 & $3.9 \pm 0.3$ \\
\hline \multicolumn{2}{|c|}{ a-Ketoglutaric acid [\%] } \\
\hline 0.05 & $0.2 \pm 0.2$ \\
\hline 0.25 & $0.1 \pm 0.1$ \\
\hline 0.5 & $0.0 \pm 0.0$ \\
\hline \multicolumn{2}{|c|}{ Propyl gallate [\%] } \\
\hline 0.005 & $1.1 \pm 0.1$ \\
\hline 0.025 & $1.3 \pm 0.3$ \\
\hline 0.05 & $1.1 \pm 0.5$ \\
\hline \multicolumn{2}{|l|}{ Ethoxyquin [\%] } \\
\hline 0.05 & $0.1 \pm 0.2$ \\
\hline 0.25 & $0.1 \pm 0.1$ \\
\hline 0.5 & $0.0 \pm 0.0$ \\
\hline \multicolumn{2}{|l|}{ DMSO [\%] } \\
\hline 0.005 & $1.0 \pm 0.04$ \\
\hline 0.025 & $0.9 \pm 0.03$ \\
\hline 0.05 & $0.8 \pm 0.06$ \\
\hline \multicolumn{2}{|c|}{ Ascorbic Acid [\%] } \\
\hline 0.005 & $0.9 \pm 0.15$ \\
\hline 0.025 & $0.9 \pm 0.2$ \\
\hline 0.05 & $0.0 \pm 0.0$ \\
\hline \multicolumn{2}{|c|}{ 3,3' Thiodipropionic Acid [\%] } \\
\hline 0.005 & $1.0 \pm 0.08$ \\
\hline 0.025 & $1.0 \pm 0.07$ \\
\hline 0.05 & $0.0 \pm 0.00$ \\
\hline \multicolumn{2}{|c|}{ Glutamate [\%] + 0,5\% Sodium Pyruvate } \\
\hline 0.1 & $160.0 \pm 21$ \\
\hline 0.5 & $450 \pm 91$ \\
\hline 1 & $884 \pm 117$ \\
\hline
\end{tabular}

Restoration ratio greater than 1.5 are displayed in Bold. Standard deviation are displayed in italic.

presence of $0.5 \%(\mathrm{w} / \mathrm{w})$ pyruvate: the culturable L. pneumophila cell count was 150 times higher on supplemented BCYE (BCYES) than the standard medium (BCYE). The cell counts on plates containing both pyruvate $(0.5 \% \mathrm{w} / \mathrm{w})$ and glutamate $(1 \% \mathrm{w} / \mathrm{w})$ were 1000 times higher than on standard medium suggesting a strong synergetic effect (Table 1).
Careful examination of BCYES plates revealed two types of colonies: colonies with diameters similar to those on standard medium (3-4 $\mathrm{mm}$ ) and colonies with very small diameters $(<1 \mathrm{~mm})$ (Figure 2$)$. Small colonies are generally indicative of lower growth rates and/or longer latency period, this observation suggests that the restored population was composed of at least two subpopulations with two different levels of physiological activity.

We evaluated the degree of restoration following treatment with, and without, various concentrations of $\mathrm{HOCl}$ (Figure 3A \& B). The recovery ratio increased from 1.6 to more than 50,000 as the $\mathrm{HOCl}$ concentration increased from 0.03 to $0.16 \mathrm{mM}$, and then dropped to 2.9 for the highest concentration of $\mathrm{HOCl}$. Interestingly, even in absence of $\mathrm{HOCl}$ treatment, a subpopulation of cells could be restored on the supplemented medium.

We assessed the degree of restoration during cell growth (Figure $3 \mathrm{C}$ ). The recovery ratio increased with the time of culture: the restored population was small for samples collected during exponential growth, but was the major subpopulation for samples collected during late stationary phase.

These results show that the culturability on standard medium of a subpopulation of VBNC cells was substantially enhanced by the presence of pyruvate and/or glutamate. Two types of colonies were observed on the supplemented medium, suggesting that the restored population was made up of two subpopulations with different levels of physiological activity.

\section{Apparently injured cells are able to invade and replicate in Amoeba}

The VBNC L. pneumophila cells described by several research groups can be resuscitated when co-cultured with Amoebae $[16,18,36,40]$. We tested whether this apparently injured subpopulation was able to invade, and replicate in, Amoebae. This subpopulation can only be detected by appropriate plating procedures, we were unable to specifically sort this subpopulation and test its specific virulence.

To overcome this difficulty, we first identified the minimal number of culturable cells allowing proliferation of L. pneumophila when co-cultured with Amoebae. Culturable cells were diluted in a suspension of $3.510^{8}$ heat-killed legionella cells. $\mathrm{ml}^{-1}$ such that there were similar numbers of cells in each sample tested. Initial CFU counts were assessed on standard medium and these mixed cell suspensions were then co-incubated with axenic cultures of $A$. castellanii. The proliferation of serially dilutions of these cultures correlated with the initial number of culturable cells: 50 to 100 times more culturable cells were observed after co-culture (Figure 4A). Moreover, no proliferation was observed for suspensions 


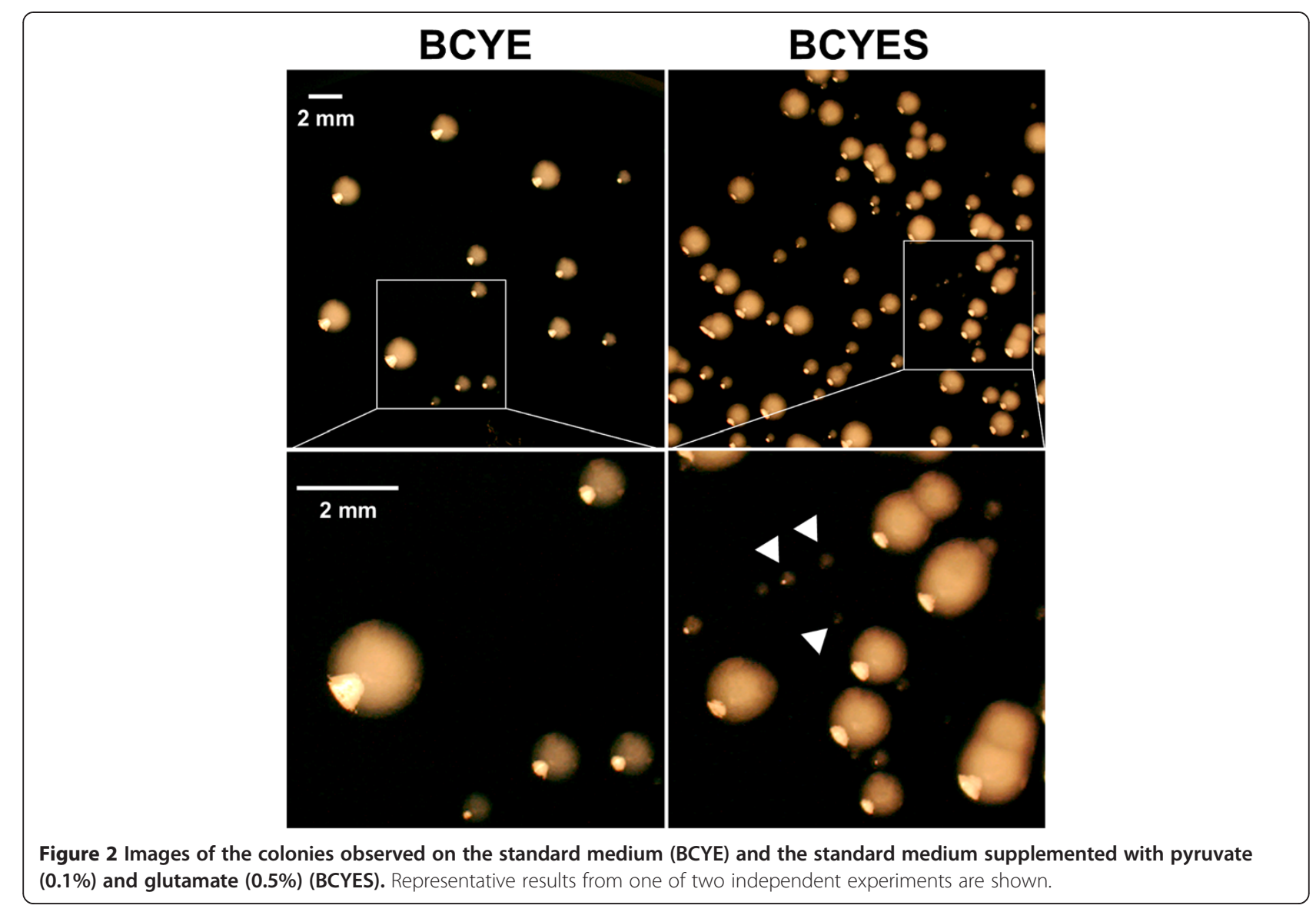

containing less than $10^{2}$ CFU.ml ${ }^{-1}$ before co-culture. This indicates that L. pneumophila proliferation in contact with A. castellanii was a function of the initial number of culturable cells and at least $10^{2}$ CFU.ml ${ }^{-1}$ is required for proliferation to be detected in our conditions.

Then, we co-incubated $\mathrm{HOCl}$-treated suspensions of L. pneumophila with axenic cultures of A. castellanii. Initial CFU counts were assessed both on standard and supplemented (BCYES) media. When CFU counts were assessed on standard medium, L. pneumophila proliferation was observed with several suspensions of L. pneumophila containing less than $10^{2}$ CFU.ml ${ }^{-1}$ and also the proliferation rates (1000 to 10000) were higher than those observed in calibrated experiments (50 to 100) (Figure 4B). This difference with the results of the calibrated proliferation experiment (Figure 4A) suggests existence of a subpopulation of cells that were not culturable on the standard medium but that were nevertheless able to infect $A$. castellanii and then grow. Part of the proliferation in this model system could therefore be interpreted in as a "resuscitation". The initial number of culturable cells assessed from CFU counts on BCYES was always higher than that observed on the standard medium (Figure $4 \mathrm{C}$ ). In this condition, no proliferation of L. pneumophila was observed after co-culture for suspensions containing less than $10^{2} \mathrm{CFU} \cdot \mathrm{ml}^{-1}$ and the proliferation rates were similar to those observed in calibrated experiments (50 to 100; Figure 4A). Thus, after $\mathrm{HOCl}$ treatment, proliferation was a function of the initial number of culturable cells assessed on the BCYES medium but not on the standard medium (BCYE). In other terms, proliferation, and as a consequence, the phenomena of resuscitation observed on the standard medium corresponded, at least in large part, to the subpopulation of cell restored (the injured cells) on the BCYES medium.

\section{Discussion}

Before the advent of single-cell based analytical methods, researchers worked mostly with pure cultures assuming that the behavior of each single cell in a population is consistent with the average behavior of all cells. However, it has been demonstrated that cell behavior in a bacterial population is divergent even under identical micro-environmental conditions. Complex phenomenon such as stochasticity in gene expression [41], asymmetrical aging [42], asymmetrical division [43], bi-stability [44] and cell differentiation [7] can lead to the formation 


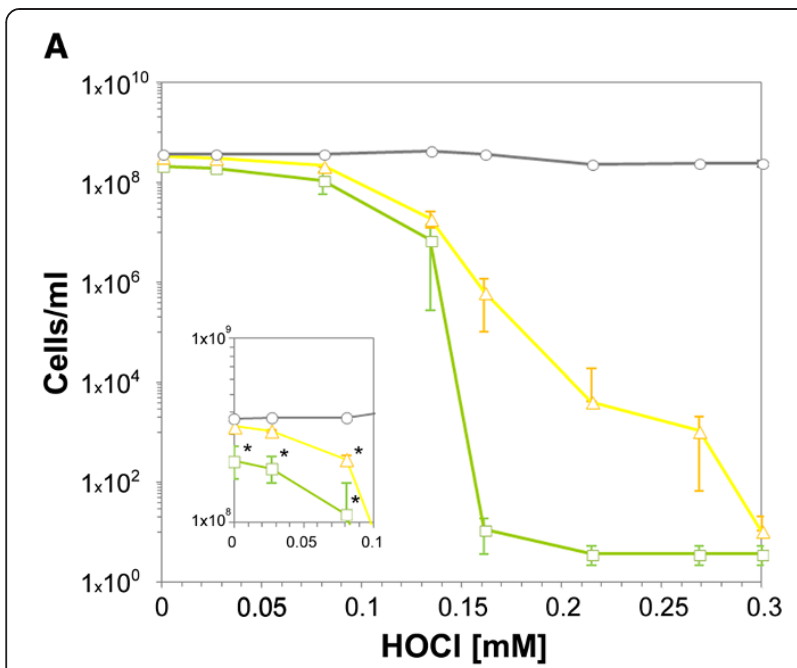

B

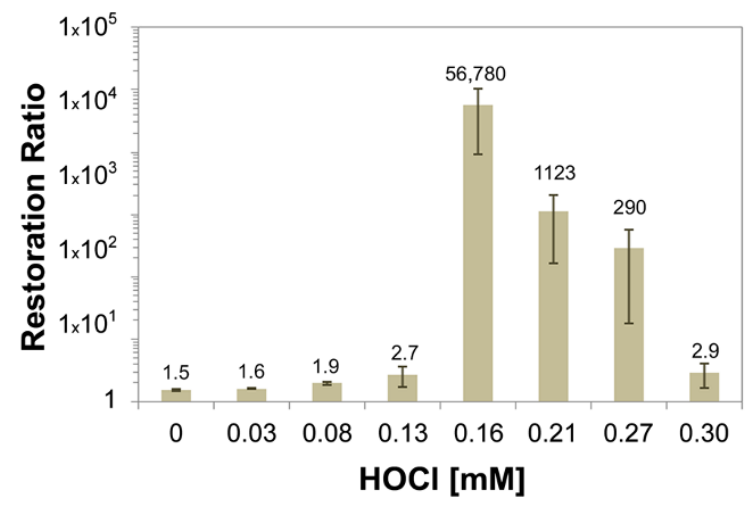

C

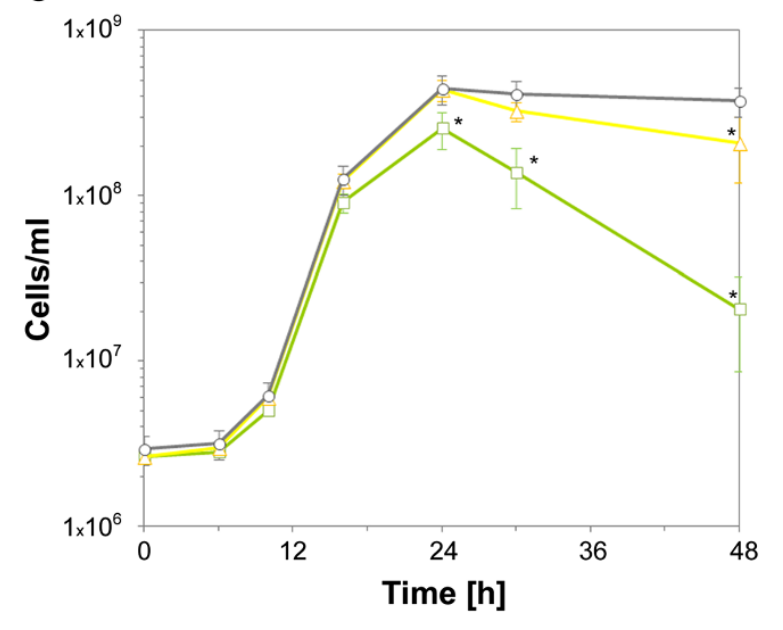

Figure 3 Restoration of the culturability of L. pneumophila Philadelphia cells on supplemented medium (BCYES). (A) Number of culturable cells observed on standard medium (口), total cells (o) and culturable cells observed on the supplemented medium $(\Delta)$ as a function of $\mathrm{HOCl}$ concentration $(\mathrm{mM})$. The results reported are means of three independent experiments. Inset shows a magnification of the region of the plots corresponding to $\mathrm{HOCl}$ concentrations lower than $0.1 \mathrm{mM}$. Stars indicate that the number of culturable cells was significantly lower $(p<0.05)$ than the total number of cells. (B) Restoration ratio (Number of culturable L. pneumophila cells on supplemented medium divided by that on standard medium) as a function of $\mathrm{HOCl}$ concentration. The restoration ratio is given above each bar. (C) Number of culturable cells as assessed on the standard medium ( $\square$ ), total cells (o) and culturable cells as assessed on the supplemented medium $(\Delta)$ as a function of time (h) for cultures in the liquid standard medium (YEC) at $37^{\circ} \mathrm{C}$. The results reported are means of three independent experiments (Errors bars $=S D$ ). Stars indicate that the number of culturable cells is significantly lower $(p<0.05)$ than the total number of cells.

of sub-populations with different cellular physiologies and/or morphologies. Unfortunately, the link between the cellular physiology and culturability of each subpopulation is not always clear, and as a consequence the characterization of VBNC cells of some organisms is complex.

VBNC L. pneumophila cells have been observed by many groups $[16,18,36,37,40]$ but the mechanisms leading to this physiological state remain unknown. It could be part of an adaptive response (A-VBNC cells), and/or a consequence of cellular deterioration (D-VBNC cells) and/or a consequence of cell death during the plating procedure (injured cells), all leading to the inability of the L. pneumophila cell affected to form a colony. In our study, we assessed the viability of L. pneumophila at the single-cell level using the CV6 procedure. By using high efficiency cell-counting procedures $(n>=3000)$, VBNC cells were detected after, but also in the absence of, biocide treatment. Interestingly, two subpopulations of cells with different levels of metabolic activity were identified among VBNC cells. These two populations displayed different resistance to the biocide treatment, suggesting that they have different physiological characteristics. We also found that pyruvate and/or glutamate were able to restore the culturability to a large proportion of the non-culturable cells observed both after, but also in the absence of, biocide treatment. Importantly, we demonstrate that the restored population was able to invade amoeba and then replicate, and that this was responsible for the "resuscitation" phenomenon. These observations strongly suggest that a suspension of $L$. pneumophila cells harvested at the beginning of stationary phase is composed of different sub-populations, with different physiological characteristics, susceptibility to stress, 


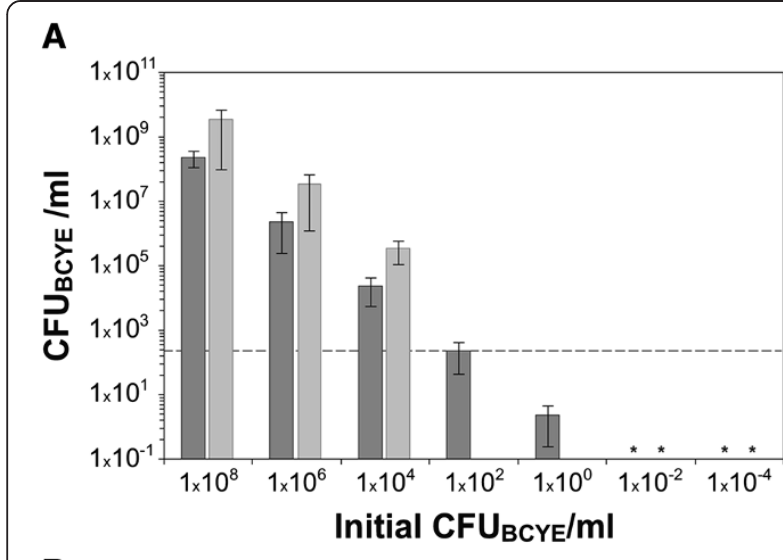

B

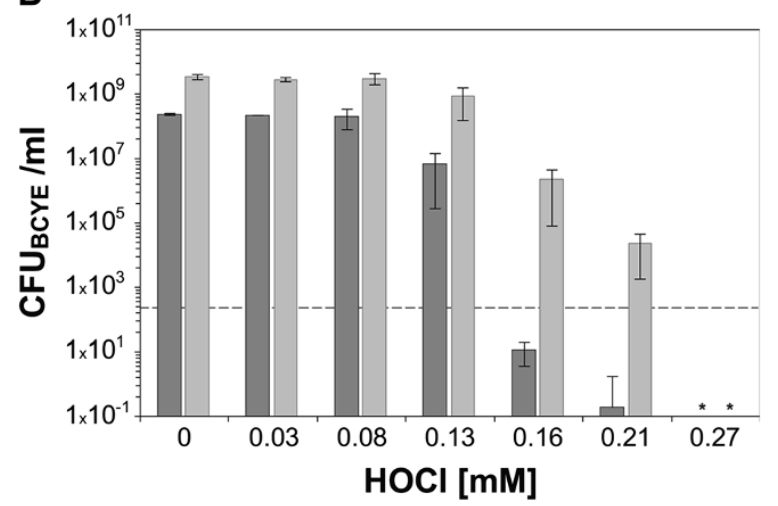

C

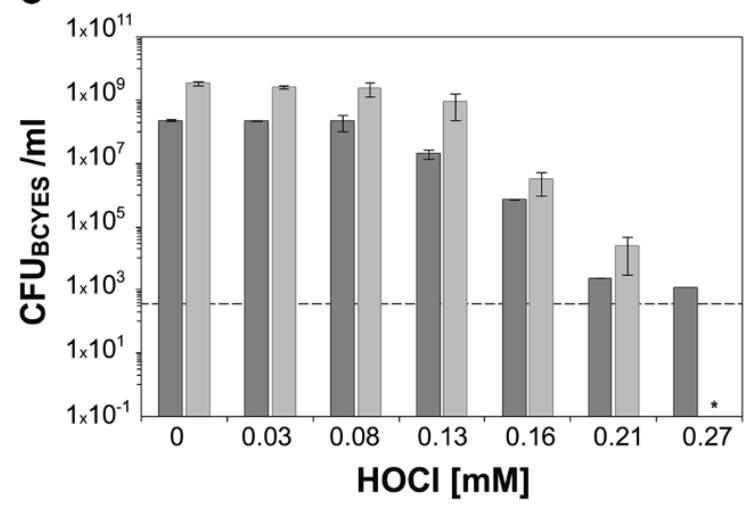

Figure 4 Proliferation of Legionella cells in co-culture with $A$. castellanii. (A) Proliferation of serially diluted culturable cells is represented as a function of the initial number of CFU as assessed on the standard medium (BCYE). (B \& C) Proliferation of cell suspensions exposed to various concentrations of $\mathrm{HOCl}$ based on the initial number of CFU as assessed on the standard medium (BCYE) (B) or the supplemented medium (BCYES) (C). Dark bars represent the initial number of CFU as assessed on the standard medium or the supplemented medium (BCYES). Gray bars represent the number of CFU as assessed on the BCYE medium after co-incubation with axenic culture of $A$. castellanii. The values reported are means for duplicate samples in three independent experiments. Error bars indicate SD and asterisks values below the detection limit $\left(<0.1\right.$ CFU.mll $\left.{ }^{-1}\right)$. culturability and ability to be restored by pyruvate and/ or glutamate.

It remains unclear exactly how pyruvate and glutamate promote restoration. Pyruvate is an antioxidant that neutralizes or prevents the formation of ROS in rich medium $[26,27,29,32,34]$. When pyruvate is converted to alanine, glutamate is concomitantly converted to $\alpha$-ketoglutarate [45], a substrate already present in the medium used for L. pneumophila (BCYE) and also used, for 25 years, in combination with charcoal to support the growth of Legionella species [46]. Keto acids prevent the toxic effects of light by inhibiting superoxide production and inhibit the rate of cysteine oxidation, an amino acid present in excess in the medium because of the cysteine auxotrophy of $L$. pneumophila species [46]. The presence of glutamate as well as pyruvate may lead to the formation of antioxidant compounds that directly or indirectly help a subpopulation of injured cells to recover during the plating procedure [26-35]. However, when other antioxidant compounds, including ascorbic acid, propyl gallate or $\alpha$-ketoglutarate, were added to the standard medium, they failed to significantly restore the culturability of non-culturable L. pneumophila cells (Table 1). Therefore, the action of pyruvate and glutamate may not be associated with their antioxidant properties. Pyruvate and glutamate may be involved in the complex life cycle of L. pneumophila. Although signal molecules that trigger L. pneumophila differentiation from the replicative to the non-replicative and transmissive form have been thoroughly studied [7,9-11], the signal triggering the reciprocal transition from the transmissive to the replicative form remains unknown. Several observations imply that amino acids are the primary signals driving differentiation from the transmissive to the replicative form of L. pneumophila, and it is therefore plausible that glutamate, one of the most abundant amino acids, might stimulate this differentiation [7]. Also, pyruvate can be converted into carbohydrates via gluconeogenesis, to the amino acid alanine, to fatty acids or to energy through acetyl-CoA. Thus, a combination of the actions of glutamate, alanine and perturbations in fatty acid metabolism [9] may act as an integrated signal to trigger the transition from the virulent to the replicative form of L. pneumophila.

\section{Conclusion}

Our results suggest that the restoration of non-culturable L. pneumophila observed in presence of pyruvate and glutamate may be a consequence of their ability to help the injured cells to recover after a stress. However, we cannot exclude the possibility that pyruvate and glutamate also drive differentiation from the transmissive to the replicative form of $L$. pneumophila. Moreover, we report evidence that this extracellular signal leads to the transition 
from a not-culturable form to a culturable form of $L$. pneumophila, providing a means for recovering virulent and previously uncultivated forms of L. pneumophila. These new media may be valuable for reducing the risks associated with underestimation of virulent cell counts of L. pneumophila in environmental samples.

\section{Methods}

\section{Strain and growth conditions}

CIP 103854 T, L. pneumophila Philadelphia was used. Bacteria were frozen at $-80^{\circ} \mathrm{C}$ until use. Bacteria were grown on buffered charcoal yeast extract (BCYE) agar plates supplemented with L-cysteine, ferric pyrophosphate and $\alpha$-ketoglutarate (OXOID) for $72 \mathrm{~h}$ at $37^{\circ} \mathrm{C}$. From solid medium, strains were grown aerobically in a rotary shaker at $37^{\circ} \mathrm{C}$ and $160 \mathrm{rpm}$ in YEC, a liquid yeast extract medium supplemented with L-cysteine, ferric pyrophosphate and $\alpha$-ketoglutarate. Overnight cultures were diluted 100-fold in YEC liquid medium and were allowed to grow for $24 \mathrm{~h}$ (to the stationary phase).

\section{Biocides challenge}

Stationary phase L. pneumophila cells were harvested from $250 \mathrm{ml}$ cultures and then washed twice with phosphate buffer $(\mathrm{pH} 7.4)$ by centrifugation at $5500 \times g$ for $10 \mathrm{~min}$ at $4^{\circ} \mathrm{C}$. Cells were resuspended and diluted in PBS pH 7.4 to an optical density of 0.2 at $600 \mathrm{~nm}(1 \times$ $10^{8}$ cells $\left.\mathrm{ml}^{-1}\right)$. These cell suspensions $(50 \mathrm{ml}$ each) were distributed into 100-ml glass flasks, and fresh $\mathrm{HOCl}$ solution (prepared the same day) was added to various concentrations from 0 to $1 \mathrm{mM}(\leq 1 \mathrm{ml})$. The samples were incubated for $1 \mathrm{~h}$ at $37^{\circ} \mathrm{C}$ in the dark with agitation (160 rpm), and the $\mathrm{HOCl}$ was then quenched by the addition of sterile sodium thiosulfate (final concentration $0.4 \mathrm{mM}$ ). Culturable bacteria were assayed by plating serial dilutions in $\mathrm{PBS}$ on $\mathrm{BCYE}$ plates at $37^{\circ} \mathrm{C}$. Colonies were counted after 3 days and 10 days of incubation at $37^{\circ} \mathrm{C}$.

\section{Viability staining procedure}

Viability of L. pneumophila was assessed using the ChemChrome V6 procedure (ChemChrome V6; CV6 - AESChemunex, Ivry-sur-seine, France) and the total number of cells was assessed using the DAPI procedure (DAPI Nucleic Acid Stain; Invitrogen). Aliquots of a suspension of $1 \times 10^{7}$ cells mll ${ }^{-1}$ were used for staining experiments. Labeling solutions were added to the samples according to the manufacturer's instructions and incubated at $37^{\circ} \mathrm{C}$ for $30 \mathrm{~min}$ in the dark; they were washed by centrifugation $(4500 \times g$ for $10 \mathrm{~min}$ in PBS pH 7.4) and transferred into 96-well glass-bottom micro plates (Greiner Bio One) previously treated with poly-L-lysine $(0.01 \%)$. To favor cell adhesion to the wells, the plates were centrifuged at $1000 \times$ $g$ for $20 \mathrm{~min}$. For each condition, the number of viable cells and the total number of cells were counted, and the results reported are mean values for three independent wells in which at least 3000 cells were analyzed. The distribution of the normalized fluorescent intensity of cells as detected by microscopy is presented as histograms. The values 0 and 1 represent the maximum and the minimum values, respectively, of fluorescence observed in all tested conditions for each experiment. The proportion of each class were normalized to the number of viable cells. The Mann-Whitney $\mathrm{U}$ test was used to assess the significance of differences in viable, total and culturable cell numbers.

\section{Fluorescence microscopy}

Microscopic analyses were performed using the automated and inverted epifluorescence microscope TE2000-E-PFS (Nikon) with the appropriate filter blocks as previously described [47]. For each sample, at least 3000 cells were examined from approximately 100 digital images taken automatically with a motorized stage (Prior Scientific), a CoolSNAP HQ 2 (Roper Scientific) and a $40 \times / 0.75$ DLL "Plan-Apochromat" or a $100 \times / 1.4$ DIC objective. Metamorph 7.5 (Molecular Devices) or NIS-Element (Nikon) software was used for digital analysis and treatment of the images to extract the number, specific fluorescence intensity and length of stained bacteria. This system allows enumeration and manual differentiation between individually labeled cells, cells in aggregations and/ or auto fluorescent particles which can interfere with automated analysis. For the CV6 procedure, cells were scored as viable if their fluorescence intensity was at least 1.5 times greater than the fluorescence background noise. Under our conditions, detection limits for CV6 measurement were $3 \times 10^{4}$ cells $\mathrm{ml}^{-1}$.

\section{Co-culture of L. pneumophila and A. Castellanii}

Axenic cultures of A. castellanii (ATCC 30234) were prepared as previously described [48]. Briefly, the $A$. castellanii strain was grown in a $150-\mathrm{cm}^{2}$ cell culture flask in PYG medium (peptone-yeast extract-glucose) at $30^{\circ} \mathrm{C}$ for 3 days. Monolayers were developed in 24-well tissue culture plates using Page's amoeba Saline (PAS) for $24 \mathrm{~h}$ at $30^{\circ} \mathrm{C}$. Aliquots of $1 \times 10^{6}$ amoebae per well in 24-well tissue culture plates were infected with $10 \times 1 \mathrm{ml}$ of $L$.

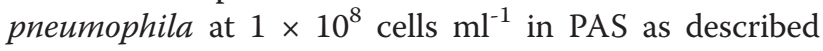
above (MOI 100). The plates were centrifuged at $500 \times$ $\mathrm{g}$ for $5 \mathrm{~min}$ and incubated for 3 days at $37^{\circ} \mathrm{C}$. Then, the monolayer and supernatant were removed and spread on BCYE agar plates. Colonies were counted after 3 days and 10 days of incubation at $37^{\circ} \mathrm{C}$.

\section{Authors' contribution}

Conceived and designed the experiments: AD, SD. Performed the experiments: AD, MC. Analyzed the data: AD, MC, SD. Wrote the paper: AD, SD. All authors read and approved the final manuscript. 


\section{Acknowledgement}

We thank Gail G. Hardy (Indiana university, Bloomington), Audrey Dumont (CNRS, Marseille), Emilie Fugier (CNRS, Marseille), and Sophie Jarraud (CNRL, France) for discussions and critical reading of the manuscript. This work was supported by a fund from the ANSES (Program ARCL-2005) and a doctoral fellowship (Adrien Ducret) from CIBA SA. We also thank Yannick Fovet for his helpful comments on the manuscript. We thank Bernard Lascola and Isabelle Pagnier for their generous gifts of LP1 and amoebae.

\section{Author details}

'Aix Marseille Université, Laboratoire de Chimie Bactérienne (UMR7283), Institut de Microbiologie de la Méditerranée - CNRS, 31, Chemin Joseph Aiguier, 13402 Marseille, France. ${ }^{2}$ Present address: Department of Biology, Indiana University, 1001 East 3rd Street, Bloomington, IN 47405 USA.

Received: 30 July 2013 Accepted: 2 December 2013

Published: 2 January 2014

\section{References}

1. Fliermans: Ecology of legionella: from data to knowledge with a little wisdom. Microb Ecol 1996, 32:203-228.

2. Muldrow LL, Tyndall RL, Fliermans CB: Application of flow cytometry to studies of pathogenic free-living amoebae. Appl Environ Microbiol 1982 44:1258-1269.

3. Fields BS, Benson RF, Besser RE: Legionella and legionnaires' disease: 25 years of investigation. Clin Microbiol Rev 2002, 15:506-526.

4. Fields BS: The molecular ecology of legionellae. Trends Microbiol 1996, 4:286-290.

5. Molmeret M, Horn M, Wagner M, Santic M, Abu Kwaik Y: Amoebae as training grounds for intracellular bacterial pathogens. Appl Environ Microbiol 2005, 71:20-28.

6. Newton HJ, Ang DKY, van Driel IR, Hartland EL: Molecular pathogenesis of infections caused by legionella pneumophila. Clin Microbiol Rev 2010, 23:274-298

7. Molofsky AB, Swanson MS: Differentiate to thrive: lessons from the legionella pneumophila life cycle. Mol Microbiol 2004, 53:29-40.

8. Brüggemann H, Hagman A, Jules M, Sismeiro O, Dillies M-A, Gouyette C, Kunst F, Steinert M, Heuner K, Coppée J-Y, Buchrieser C: Virulence strategies for infecting phagocytes deduced from the in vivo transcriptional program of legionella pneumophila. Cell Microbiol 2006, 8:1228-1240.

9. Edwards RL, Dalebroux ZD, Swanson MS: Legionella pneumophila couples fatty acid flux to microbial differentiation and virulence. Mol Microbiol 2009, 71:1190-1204.

10. Byrne B, Swanson MS: Expression of legionella pneumophila virulence traits in response to growth conditions. Infect Immun 1998, 66:3029-3034.

11. Hammer BK, Swanson MS: Co-ordination of legionella pneumophila virulence with entry into stationary phase by ppGpp. Mol Microbiol 1999, 33:721-731.

12. Faulkner G, Berk SG, Garduño E, Ortiz-Jiménez MA, Garduño RA: Passage through tetrahymena tropicalis triggers a rapid morphological differentiation in legionella pneumophila. J Bacterio/ 2008, 190:7728-7738.

13. Kim BR, Anderson JE, Mueller SA, Gaines WA, Kendall AM: Literature review-efficacy of various disinfectants against legionella in water systems. Water Res 2002, 36:4433-4444.

14. Lin YE, Stout JE, Yu VL: Controlling legionella in hospital drinking water: an evidence-based review of disinfection methods. Infect Control Hosp Epidemiol 2011, 32:166-173.

15. Hwang MG, Katayama H, Ohgaki S: Effect of intracellular resuscitation of legionella pneumophila in acanthamoeba polyphage cells on the antimicrobial properties of silver and copper. Environ Sci Technol 2006, 40:7434-7439

16. García MT, Jones S, Pelaz C, Millar RD, Abu Kwaik Y: Acanthamoeba polyphaga resuscitates viable non-culturable legionella pneumophila after disinfection. Environ Microbiol 2007, 9:1267-1277.

17. Allegra S, Berger F, Berthelot P, Grattard F, Pozzetto B, Riffard S: Use of flow cytometry to monitor legionella viability. Appl Environ Microbiol 2008, 74:7813-7816.

18. Alleron L, Merlet N, Lacombe C, Frère J: Long-term survival of legionella pneumophila in the viable but nonculturable state after monochloramine treatment. Curr Microbiol 2008, 57:497-502.
19. Gião MS, Wilks SA, Azevedo NF, Vieira MJ, Keevil CW: Validation of SYTO 9/propidium iodide uptake for rapid detection of viable but noncultivable legionella pneumophila. Microb Ecol 2009, 58:56-62.

20. Oliver JD: Recent findings on the viable but nonculturable state in pathogenic bacteria. FEMS Microbiol Rev 2010, 34:415-425.

21. Roszak DB, Colwell RR: Survival strategies of bacteria in the natural environment. Microbiol Rev 1987, 51:365-379.

22. Mukamolova GV, Kaprelyants AS, Kell DB, Young M: Adoption of the transiently non-culturable state-a bacterial survival strategy? Adv Microb Physiol 2003, 47:65-129.

23. Desnues B, Cuny C, Grégori G, Dukan S, Aguilaniu H, Nyström T: Differential oxidative damage and expression of stress defence regulons in culturable and non-culturable Escherichia coli cells. EMBO Rep 2003, 4:400-404.

24. Nyström T: Nonculturable bacteria: programmed survival forms or cells at death's door? Bioessays 2003, 25:204-211.

25. Cuny C, Dukan L, Fraysse L, Ballesteros M, Dukan S: Investigation of the first events leading to loss of culturability during Escherichia coli starvation: future nonculturable bacteria form a subpopulation. J Bacteriol 2005, 187:2244-2248.

26. Bang $W$, Drake $M A$, Jaykus $L A$ : Recovery and detection of vibrio vulnificus during cold storage. Food Microbiol 2007, 24:664-670.

27. Calabrese JP, Bissonnette GK: Improved detection of acid mine water stressed coliform bacteria on media containing catalase and sodium pyruvate. Can J Microbiol 1990, 36:544-550.

28. Cuny C, Lesbats M, Dukan S: Induction of a global stress response during the first step of Escherichia coli plate growth. Appl Environ Microbiol 2007, 73:885-889.

29. Czechowicz SM, Santos O, Zottola EA: Recovery of thermally-stressed Escherichia coli $0157: \mathrm{H7}$ by media supplemented with pyruvate. Int J Food Microbiol 1996, 33:275-284.

30. Dukan S, Belkin S, Touati D: Reactive oxygen species are partially involved in the bacteriocidal action of hypochlorous acid. Arch Biochem Biophys 1999, 367:311-316.

31. Gogniat G, Dukan S: TiO2 photocatalysis causes DNA damage via fenton reaction-generated hydroxyl radicals during the recovery period. Appl Environ Microbiol 2007, 73:7740-7743.

32. Lee RM, Hartman PA: Optimal pyruvate concentration for the recovery of coliforms from food and water. Journal of food protection 1989, 52(2):119-121.

33. Maalej S, Gdoura R, Dukan S, Hammami A, Bouain A: Maintenance of pathogenicity during entry into and resuscitation from viable but nonculturable state in aeromonas hydrophila exposed to natural seawater at low temperature. J Appl Microbiol 2004, 97:557-565.

34. McDonald LC, Hackney CR, Ray B: Enhanced recovery of injured Escherichia coli by compounds that degrade hydrogen peroxide or block its formation. Appl Environ Microbiol 1983, 45:360-365.

35. Teo AY, Ziegler GR, Knabel SJ: Optimizing detection of heat-injured listeria monocytogenes in pasteurized milk. J Food Prot 2001, 64:1000-1011.

36. Hay J, Seal DV, Billcliffe B, Freer JH: Non-culturable legionella pneumophila associated with acanthamoeba castellanii: detection of the bacterium using DNA amplification and hybridization. J Appl Bacteriol 1995, 78:61-65.

37. Steinert M, Emödy L, Amann R, Hacker J: Resuscitation of viable but nonculturable legionella pneumophila Philadelphia JR 32 by acanthamoeba castellanii. Appl Environ Microbiol 1997, 63:2047-2053.

38. Johnson PE, Deromedi AJ, Lebaron P, Catala P, Cash J: Fountain flow cytometry, a new technique for the rapid detection and enumeration of microorganisms in aqueous samples. Cytometry A 2006, 69:1212-1221.

39. Parthuisot N, Catala P, Lemarchand K, Baudart J, Lebaron P: Evaluation of ChemChrome V6 for bacterial viability assessment in waters. J Appl Microbiol 2000, 89:370-380.

40. Steinert M, Ockert G, Lück C, Hacker J: Regrowth of legionella pneumophila in a heat-disinfected plumbing system. Zentralbl Bakteriol 1998, 288:331-342.

41. Elowitz MB, Levine AJ, Siggia ED, Swain PS: Stochastic gene expression in a single cell. Science 2002, 297:1183-1186.

42. Nyström T: A bacterial kind of aging. PLoS Genet 2007, 3:e224.

43. Hughes V, Jiang C, Brun Y: Caulobacter crescentus. Curr Biol 2012, 22:R507-509.

44. Dubnau D, Losick R: Bistability in bacteria. Mol Microbiol 2006, 61:564-572. 
45. Kim SH, Schneider BL, Reitzer L: Genetics and regulation of the major enzymes of alanine synthesis in Escherichia coli. J Bacteriol 2010 192:5304-5311.

46. Pine L, Hoffman PS, Malcolm GB, Benson RF, Franzus MJ: Role of keto acids and reduced-oxygen-scavenging enzymes in the growth of legionella species. J Clin Microbiol 1986, 23:33-42

47. Ducret A, Maisonneuve E, Notareschi P, Grossi A, Mignot T, Dukan S: A microscope automated fluidic system to study bacterial processes in real time. PLOS ONE 2009, 4:e7282.

48. La Scola B, Mezi L, Weiller PJ, Raoult D: Isolation of legionella anisa using an amoebic coculture procedure. J Clin Microbiol 2001, 39:365-366.

doi:10.1186/1471-2180-14-3

Cite this article as: Ducret et al:: Characterization and resuscitation of 'non-culturable' cells of Legionella pneumophila. BMC Microbiology 2014 14:3.

\section{Submit your next manuscript to BioMed Central and take full advantage of:}

- Convenient online submission

- Thorough peer review

- No space constraints or color figure charges

- Immediate publication on acceptance

- Inclusion in PubMed, CAS, Scopus and Google Scholar

- Research which is freely available for redistribution 